Research article

\title{
Day/night melatonin content in cerebral palsy
}

\author{
Janaina S. Santos ${ }^{\mathrm{a}, \mathrm{b}}$, Celia M. Giacheti ${ }^{\mathrm{b}}$, Lilian S. Dornelas ${ }^{\mathrm{a}, \mathrm{b}}$, Nathani C. Silva ${ }^{\mathrm{b}}$, \\ Ana L.D.M. Souza ${ }^{\mathrm{b}}$, Leila M. Guissoni Campos ${ }^{\mathrm{c}}$, Luciana Pinato ${ }^{\mathrm{b}, *}$ \\ a Specialized Center for Rehabilitation, Sorri-Bauru-SP, Brazil \\ ${ }^{\mathrm{b}}$ São Paulo State University-UNESP, Marília, SP, Brazil \\ ${ }^{\mathrm{c}}$ University of Marília-UNIMAR, Marília, SP, Brazil
}

A R T I C L E IN F O

\section{Keywords:}

Melatonin

Sleep

Neurodevelopment

Behavior

Cerebral palsy

\begin{abstract}
A B S T R A C T
Changes in the sleep-wake cycle are frequent and may impair quality of life in individuals with cerebral palsy (CP). To investigate if a lack of a day/night variation of melatonin content could be related with sleep disorders (SD), the SD were evaluated with a Sleep Questionnaire and the melatonin content using ELISA in 33 individuals with CP and 24 controls. The indicative of SD were present in 47\% of CP group, and the most frequent was the indicative of sleep breathing disorder. The CP group showed higher diurnal and lower nocturnal melatonin content than controls. Individuals with CP that had indicative of SD showed lower nocturnal content of melatonin than those without SD. These results showed that the lack of the day/night variation of melatonin was related to SD in individuals with $\mathrm{CP}$.
\end{abstract}

\section{Introduction}

Cerebral palsy (CP), defined as non-progressive brain injury caused by pre-, peri- or post-natal etiological factors in the developing brain, affects the functioning of individuals, resulting in permanent disorders of movement and posture at different levels [1]. In addition to motor impairment, also sensory, perceptual, cognitive, communicative and behavioral disorders can be manifested in CP [2].

Among the behavioral aspects, sleep, which is a biological phenomenon determined by a complex neural network, may also be altered in this population. Complaints about changes in the sleep-wake cycle are frequent and may impair quality of life in the $\mathrm{CP}$, influencing aspects of physical and emotional well-being [3,4].

Until the present moment, the various hypotheses about the possible nature of sleep disorders (SD) in cerebral palsy include that SD could be a result of primary brain injuries, such as lesions of pathways and/or structures responsible for or related to the control of biological rhythms [5]. For example, the disorder of impaired initiation of sleep (DIMS) could be linked to blindness or visual impairment with altered light perception [6].

In addition to this, some children with $\mathrm{CP}$ have other multiple risk factors that predispose them to SD. The presence of epilepsy per se disrupts sleep and antiepileptic drugs adversely affect sleep quality, which in turn exacerbates the epilepsy $[7,8]$. Sleep quality can also be affected by generalized abnormality of muscle tone or an abnormal neuromuscular control of their upper airway that can lead to sleep breathing disorder in CP $[9,10]$. These children regularly encounter pain during sleep as a result of muscle spasms; postural equipment used overnight and gastro-esophageal reflux [9]. Additionally, extrinsic aspects, specifically environmental and family members and clinical and surgical interventions, could affect sleep quality [11].

Another hypothesis for sleep problems in CP could be an abnormal production of the hormone melatonin. In spite of the fact that in several pathologies it is clear that the presence of sleep disorders may be related to low levels of melatonin [12,13], this question has not been investigated in this population until this moment.

In normal subjects, melatonin is produced at night by the pineal gland under rhythmic control of the suprachiasmatic nucleus and the light/dark cycle and regulates several circadian rhythms, including the sleep-wake cycle [14,15]. Normal melatonin synthesis begins in line with increased sleep propensity, while, on the other hand, sleep consolidation deficiencies are related to lower melatonin secretion $[16,17]$. But, pro-inflammatory cytokines can disrupt the normal production of melatonin by the pineal gland, leading to a decrease in nocturnal melatonin plasma level and an eventual raise in the daytime level $[18,19]$ resulting in sleep problems found in some pathological conditions [20].

Regarding the consequences of sleep disorders in children, it is known that effects may include poor growth and behavioral problems such as mood changes; decreased motivation, concentration and

\footnotetext{
* Corresponding author at: Av. Hygino Muzzi Filho, 737, Mirante, Marília, SP, Brazil.

E-mail address: lpinato@marilia.unesp.br (L. Pinato).
} 
alertness; memory and communication deficits; immunity decline; motor performance changes; worsened mental health; and poor quality of life for the child and family [21-23].

Since the performance in therapies and technical follow ups performed may determine better or worse overall development [24], it is important to evaluate the presence and the causes of SD in the CP patient to indicate interventions to minimize and / or remedy such problems. Therefore, the present study aimed to investigate and relate sleep disorders with melatonin content in individuals with CP.

\section{Methods}

\subsection{Procedure}

For the investigation of sleep-wake patterns, the Sleep Habits Questionnaire [25] and the Sleep Disorders Scale for Children (SDSC) [26] were used, both validated for Portuguese and answered by parents.

The SDSC consists of 26 items for the evaluation of sleep in children and adolescents aged 3-18 years; each item is numbered with a score of one (never) to five (always) by the frequency with which one of them has occurred in the last six weeks. The scores are grouped into seven categories: disorders of initiating and maintaining sleep (DIMS), sleepbreathing disorders (SBD), disorders of arousal (DA), sleep-wake transition disorders (SWTD), disorders of excessive somnolence (DES), sleep hyperhidrosis (SHY) and an overall score (TS) [26]. The original scale was designed for school-age children, and the Portuguese version was validated in children aged 3-16 years [26]. In our study, preschoolers were also included because they had similar routines, especially in relation to the time of the class start.

For saliva collection, individually labeled salivette kits (SARSTEDT, Nümbrecht, Germany) were used. The collection was performed by parents at home at 1 a.m and 1 p.m. The nocturnal collection was performed with dim light with the goal of not disturbing pineal synthesis of melatonin. Quantification of salivary melatonin was performed using commercial ELISA kits according to the manufacturer's instructions (IBL, Hamburg, Germany), and the results were described in $\mathrm{pg} / \mathrm{mL}$.

In the characterization of the sample the Gross Motor Function Classification System (GMFCS) and the Gross Motor Function Measure (GMFM) were used $[27,28]$. Both procedures analyze motor characteristics complementarily, since the GMFM provides one quantitative classification of motor skills and the GMFCS provides the level of severity of movement dysfunction.

For investigation of communication function, the classification system of the Communication Function for Individuals with Cerebral Palsy (CFCS) version for Portuguese [29] was applied, which classifies the performance of individuals with CP in five levels: CFCS Level I represents a person that independently and effectively alternates between producing and receiving information with most people in most environments. CFCS Level II represents a person that independently alternates between producing and receiving information with most people in most environments, but the conversation may be slower. CFCS Level III represents a person that usually communicates effectively with familiar communication partners but not unfamiliar partners in most environments. CFCS Level IV represents a person that is not always consistent in communicating with familiar communication partners. CFCS Level V represents a person that is seldom able to communicate effectively even with familiar people [30].

Communication included speech, vocalization, gesture, facial expression and augmentative and alternative communication to supplement their natural forms of communication. Level I indicates that the individual communicates better than an individual at Level V [30].

The CFCS can be applied according to the perception of the parents, professionals that know about the communication of the individual or, in some cases, the individuals with $\mathrm{CP}$, being that performance in communication should be based on the daily routine of these

Table 1

Medication with some influence in sleep in individuals of CP group. * Means that this medication cause drowsiness.

\begin{tabular}{|c|c|}
\hline Fexofenadine * $(1$ individual $)$ & Methylphenidate (2 individuals) \\
\hline Amitriptyline ( 1 individual) & Montelukast sodium ( 1 individual) \\
\hline Baclofen*( 9 individuals $)$ & Nitrazepam* (1 individual) \\
\hline Biperiden* (4 individuals) & Phenobarbital* ( 1 individual) \\
\hline 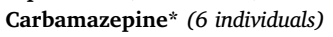 & Risperidone* (2 individuals) \\
\hline Clonazepam* (2 individuals) & Sertraline* (1 individual) \\
\hline Desloratadine* (1 individual) & Topiramate* (1 individual) \\
\hline Depakote* (3 individuals) & Urbanyl*(1 individual) \\
\hline Domperidone ( 1 individual) & Valproate* (6 individuals) \\
\hline Hydantal* ( 1 individual) & Vigabatrin* ( 1 individual) \\
\hline
\end{tabular}

individuals at home, school or community [31].

\subsection{Sample description}

The inclusion criteria for the sample with cerebral palsy were individuals with a medical diagnosis of $\mathrm{CP}(\mathrm{N}=33)$, without uncontrolled epilepsies aged between three and 12 years old (17 males and 16 females), full-term and without blindness. This group was recruited from April 2016 to October 2016 from a clinical population referred to one public institution of rehabilitation, where the sleep pattern and motor and communication data were collected. From a total of 40 parents approached, 33 accepted to participate in the study.

Approximately $72 \%$ of $\mathrm{CP}$ group used medication that had effects in sleep, mainly somnolence (Table 1 ). Regarding the nutritional diagnosis, $60.5 \%$ of the CP group had a eutrophic evaluation and $33.5 \%$ presented a risk for malnutrition and being underweight, while $6 \%$ was obesity. During the physical examination the parents were asked if the child complains of pain and there was no report by parents of presence of pain in the sample.

Around $65 \%$ of individuals with CP presented gross motor function evaluated by GMFM to be 88 , inferior to that expected for age.

The motor function analysis through GMFCS showed that $9.4 \%$ of the individuals with CP presented as Level I; $18.8 \%$ presented as Level II; $25 \%$ presented as Level III; $15.6 \%$ presented as Level IV and $34.4 \%$ presented as Level V in the GMFCS (Table 2). Regarding the classification of the communication function through the CFCS, it was verified that $31.2 \%$ of the individuals with $\mathrm{CP}$ presented as Level I; $12.5 \%$ presented as Level II; $12.5 \%$ presented as Level III; 0\% presented as Level IV and $46.9 \%$ presented as Level V (Table 2).

The control group consisted of the same percentage of genders and without age difference of the $\mathrm{CP}$ group. A total of 24 typical development (TD) children, full-term, whose parents accepted to participate in the study were recruited from normal schools.

The exclusion criteria adopted for both groups were individuals who use melatonin or drugs that interfere in the melatonin synthesis pathway.

The present research was approved by the Research Ethics Committee of the São Paulo State University (UNESP), proc. ํำ126883/ 2015. All responsible participants signed the consent form.

Table 2

Percentage (\%) of individuals with Cerebral Palsy (CP) in each classification of Gross Motor Function Classification System (GMFCS) and Communication Function Classification (CFCS).

Gross Motor Function Classification System (GMFCS)

\section{Classification}

GMFCS I

GMFCS II

GMFCS III

GMFCS IV

GMFCS V

\% of individuals
9.4
18.8
25
15.6
34.4

System of Communication Function for Individuals with CP (CFCS)

\begin{tabular}{ll}
\hline Classification & \% of individuals \\
CFCS I & 31.2 \\
CFCS II & 12.5 \\
CFCS III & 12.5 \\
CFCS IV & 0 \\
CFCS V & 46.9
\end{tabular}


Table 3

DIMS- disorders of initiating and maintaining sleep; SBD sleep-breathing disorders; DA disorders of arousal; SWTD - sleep - wake transition disorders; DES disorders of excessive somnolence; SHY - sleep hyperhidrosis; TS - overall score. $\mathrm{CP}=$ cerebral Palsy, TD = typical development.

\begin{tabular}{llllllll}
\hline Categories & DIMS & SBD & DA & SWTD & DES & SHY & TS \\
\hline Abnormal CP (\%) & 0 & 65.6 & 6.25 & 3.2 & 3.2 & 37.5 & 47.0 \\
Abnormal TD (\%) & 4.2 & 12.5 & & & & 4.2 & 12.5 \\
\hline
\end{tabular}

Sleep disorders in CP or TD children according to Sleep Disorders Scale for Children.

\subsection{Analysis of results}

Data were expressed as the mean \pm standard error of the mean. Comparative analyses of melatonin were performed by repeated-measures analysis of variance (rANOVA) followed by Newman Keuls post test, and values were considered significantly different at $\mathrm{P}<0.05$.

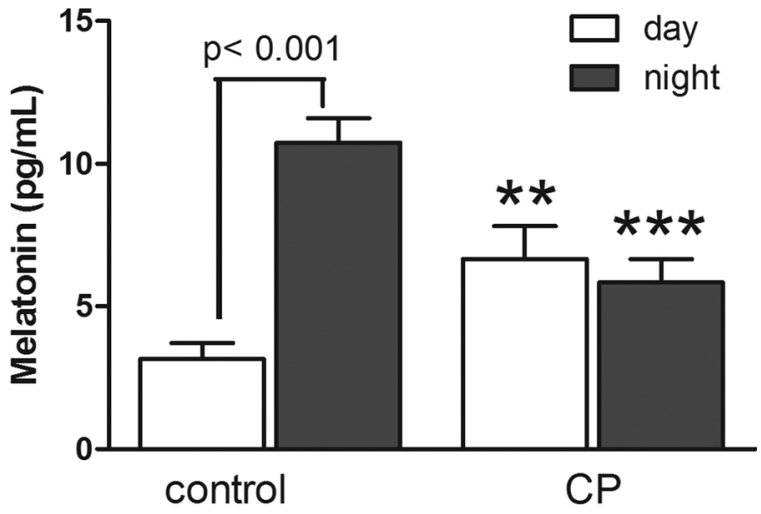

Fig. 2. Mean \pm standard error of mean of salivary melatonin content $(\mathrm{pg} / \mathrm{mL})$ in control $(\mathrm{N}=15)$ and cerebral palsy $(\mathrm{CP}, \mathrm{N}=20)$; ** mean $\mathrm{CP} \neq$ control, $\mathrm{P} \leq 0.01 ; * * *$ mean $\mathrm{CP} \neq$ control, $\mathrm{P} \leq 0.001$.
A
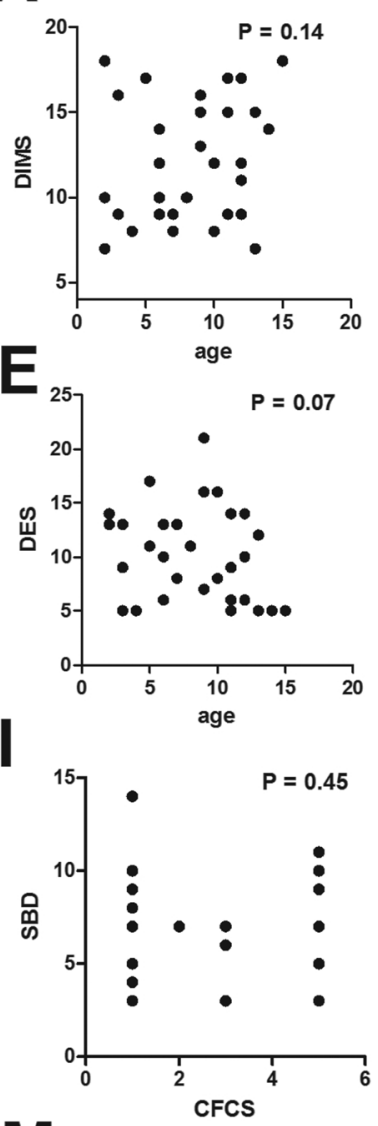

M

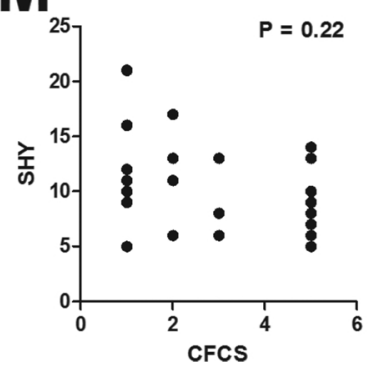

B
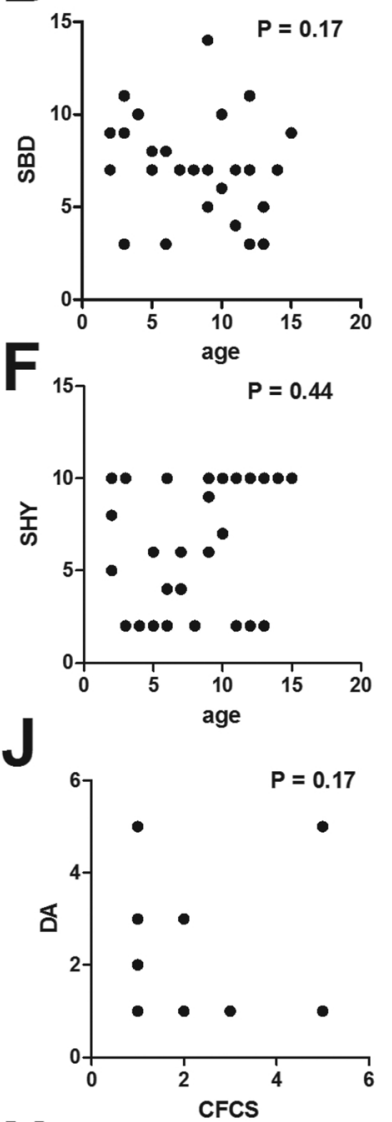

$\mathbf{N}$

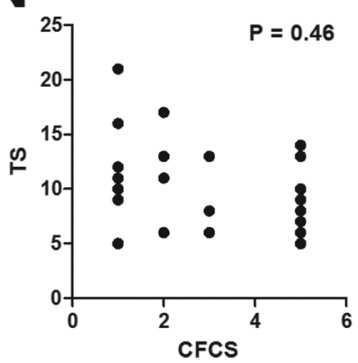

C
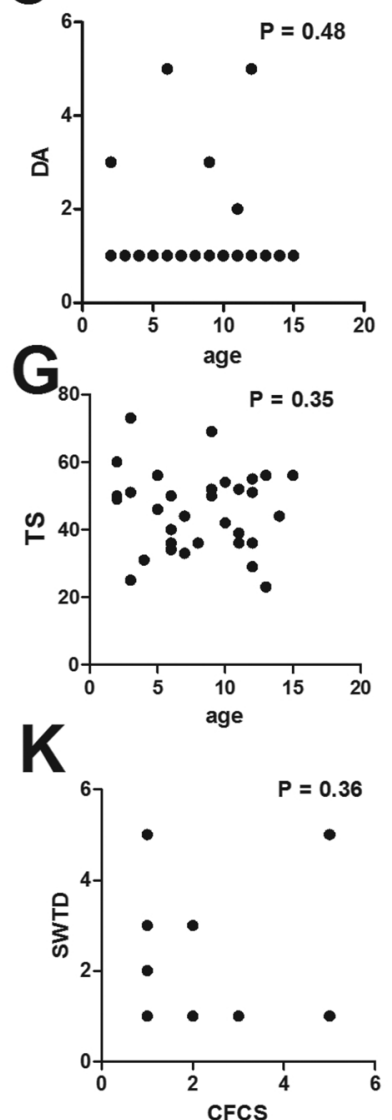

D
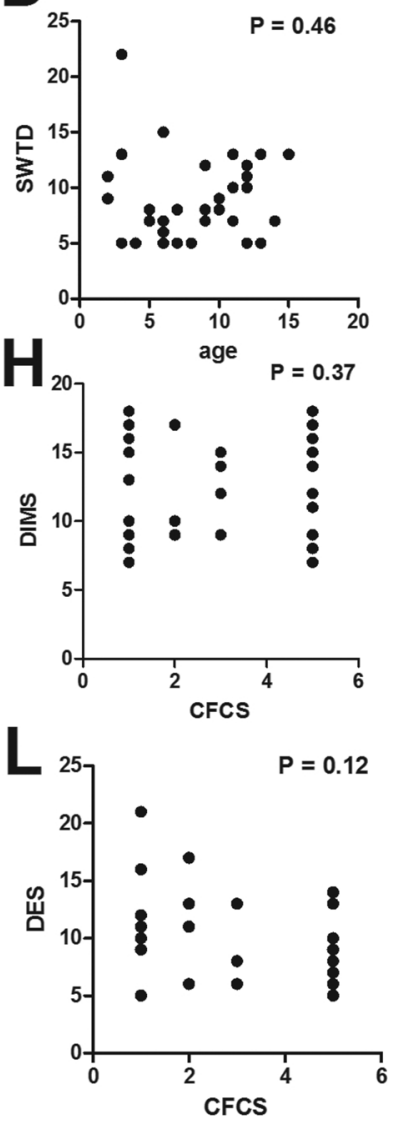

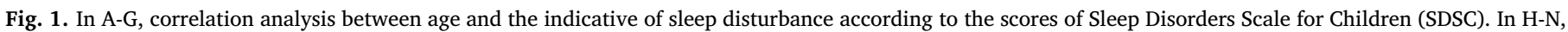

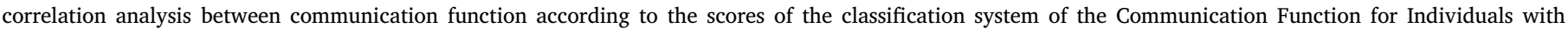
Cerebral Palsy (CFCS) and the indicative of sleep disturbance according to SDSC, $\mathrm{N}=33$. 
A

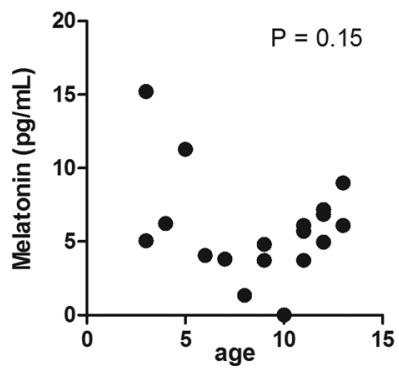

B

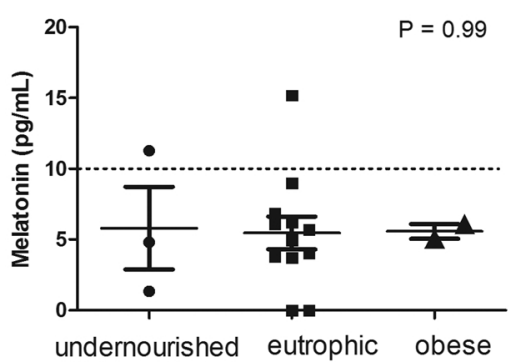

C

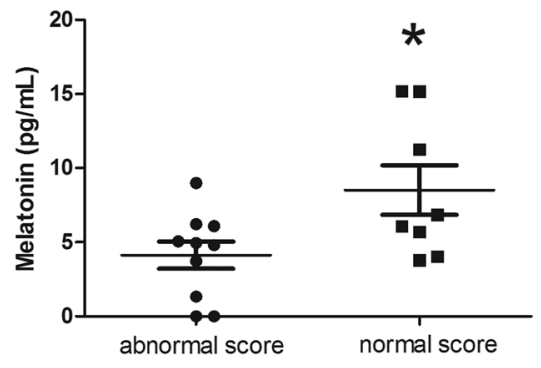

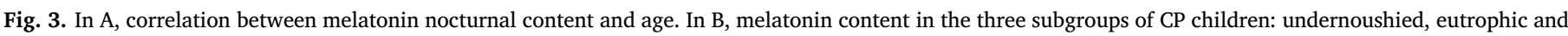

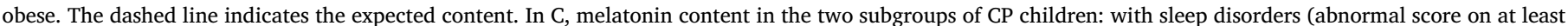
one SDSC factor) and without sleep disorders, * means $\mathrm{p}<0.05$.

The results are also shown as percentages relative to the total number of participants of the group. Multiple correlation analyses between age, motor classifications and the variables sleep, communication, gender and melatonin were used at the $5 \%$ significance level.

\section{Results}

The investigation of the presence of sleep disorders showed that an abnormal total sleep score was found in $47 \%$ of the children with CP and that $78 \%$ of these children had an abnormal score on at least one SDSC factor. The most frequent factors were SBD, present in $65.6 \%$ of individuals with $\mathrm{CP}$, and SHY, which was present in $37.5 \%$. DA disorders were also found in $6.2 \%$, and SWTD and DES were found in $3.2 \%$ of individuals with CP. In the TD group $12.5 \%$ of children showed abnormal total sleep score, $4.2 \%$ showed SBD and $4.2 \%$ showed SHY (Table 3).

Regarding sleep quality, it was also found that mean latency time of individuals with $\mathrm{CP}$ was $24.8 \pm 2.3 \mathrm{~min}$, and in the control group, the mean was $8.8 \pm 1.1 \mathrm{~min}$. There was no correlation between age and the scores of sleep disturbances (Fig. 1A-G). Also, there was no correlation between the presence of sleep disorders and the communication function in the children (Fig. $1 \mathrm{H}-\mathrm{N}$ ).

In the analysis of the salivary content of melatonin, it was found that the CP group presented higher diurnal content (CP $6.7 \pm 1.2$ vs control $3.1 \pm 0.7 \mathrm{pg} / \mathrm{mL}, \mathrm{p}<0.05$ ) and lower nocturnal content (CP $5.8 \pm 0.8$ vs control $10.7 \pm 0.9 \mathrm{pg} / \mathrm{mL}, \mathrm{p}<0.0001$ ) of melatonin, relative to the control group. In addition, unlike the control group, the $\mathrm{CP}$ group did not exhibit a day/night difference in melatonin content (Fig. 2). Melatonin was not correlated with age (Fig. 3A), and it did not seem to be determined by nutritional aspects of the $\mathrm{CP}$ children, since the nocturnal blockage is present in the following three subgroups of $\mathrm{CP}$ children: undernourished, eutrophic and obese (Fig. 3B).

The possible relationship between SD and melatonin content showed that individuals with $\mathrm{CP}$ who presented with SD had lower nocturnal content of melatonin (Fig. 3C).

\section{Discussion}

The present study showed a higher percentage of SD in children with CP than in children with TD, which was in agreement with the literature that shows that these children exhibit more sleep disorders than typically developing children [32,33].

At pre-school age, children with $\mathrm{CP}$ (mean age $3.8 \pm 0.8$ years) already present a high incidence of SD, with over $30 \%$ presenting at least one sleep disorder [34]. In studies with older children this percentage increase since more than $40 \%[7,35]$ and over $70 \%$ of the children in the present study presented at least one clinically significant sleep disorder. The higher incidence of sleep disorders in children with $\mathrm{CP}$ in the present study is most likely due the differences in the socioeconomic status, environment, and personal supports of the children from different countries, which are known to have influence on sleep $[11,25,36,37]$.

The indicative of sleep-breathing disorders were highly present in $65.5 \%$ of individuals with $\mathrm{CP}$ in the present study. The higher incidence of SD, mainly SBD in older CP children, already reported in previous studies $[7,38]$, is probably related to the unfavorable progress of airway obstruction due to increasing muscular hypotonia with age [39]. This is worrisome since, despite characteristics such as issues of tonicity, muscle changes and respiratory muscle incoordination that make these children susceptible to obstructive sleep apnea (OSA) and others sleep disturbances $[10,22,39,40]$, the awareness among clinicians is patchy, and many children with neurodisability have sleep breathing problems that remain undiagnosed and untreated [40]. A multifactorial approach is required when dealing with sleep in this patient subgroup; a polysomnography investigation is the best diagnostic clinical test and should be used in further investigation. If confirmed, an ear, nose and throat review followed by positive pressure therapy of continuous positive airway pressure (CPAP)/noninvasive ventilation (NIV) therapy are treatment options [41]. This therapy can improve quality of life as a direct consequence of improving sleep routine [24].

Another frequent disturbance found in this population was sleep hyperhidrosis. It is known that the sleep hyperhidrosis disorder may be related to lesions of the mesencephalic pathways and structures reaching hypothalamic nuclei that are responsible for the thermoregulation and regulation of hydrolysis [42].

Disorders of sleep-wake transition, excessive somnolence and disorders of arousal were also found in individuals with $\mathrm{CP}$ in the present study. The difficulty in initiating and maintaining sleep seems to also be one of the characteristics of sleep in this population. In the present study, this difficulty was identified with the application of the Sleep Habits Questionnaire, in which it was observed that the latency to initiate sleep exhibited by individuals with $\mathrm{CP}$ was higher than in the control group. None of these sleep disturbances were related to the evaluated communication function.

It is important to note that sleep disorders like insomnia may be masked by the use of frequent medications in this population, such as antihistamine, hypnotic, antispastic, antipsychotic, anticonvulsant and antidepressant medications found in this study, which may present effects or side effects of sleepiness [40].

It is known that pain interferes with sleep and there is evidence that this may be a bidirectional relationship and should be taken into account when discussing sleep problems [43] however, in the present study, there was no report by parents of presence of pain in the sample. To investigate the possible causes of sleep disorders in this population, 
the hormone melatonin was measured since a relation between sleep disorders and low levels of melatonin has already been demonstrated in several pathologies such as autism spectrum disorder [12,13]. This was the first study to explore the relation between melatonin and sleep disturbance in CP children, and the results showed that individuals with CP had an absence of day/night rhythmicity and lower nocturnal content of salivary melatonin compared to the control group. The causes for this blockage should be explored in the future. One hypothesis is that high levels of pro-inflammatory cytokines could disrupt the normal production of melatonin, leading to a decrease in the nocturnal melatonin plasma level and an eventual rise in the daytime level $[18,19]$.

Based on these results, new studies exploring the pharmacological use of melatonin should be developed in this population, since melatonin replacement may be a good strategy, by taking into account the results of improved sleep quality and consequently behavioral and cognitive outcomes obtained in other populations showing how melatonin may be useful in the treatment of sleep problems in children $[12,44]$.

The results of the present study showing, for the first time, that a lower content of melatonin could be the cause of SD in CP should not be ignored in multidisciplinary therapies since these disorders are one of the main complaints of caregivers [45] and are known to worsen the clinical and functional status of individuals with CP [23].

\section{Declaration of interest}

The authors report no declarations of interest

\section{References}

[1] M. Bax, M. Goldstein, P. Rosenbaum, A. Leviton, N. Paneth, B. Dan, et al., Proposed definition and classification of cerebral palsy, Dev. Med. Child Neurol. 47 (2005) $571-576$.

[2] P. Rosenbaum, N. Paneth, A. Leviton, M. Goldstein, M. Bax, A report: the definition and classification of cerebral palsy April 2006, Dev. Med. Child Neurol. 109 (2007) 8-14.

[3] G.M. Zuculo, F.C.C. Knap, L. Pinato, Correlation between sleep and quality of life in cerebral palsy, CoDAS 26 (2014) 447-456.

[4] S.F. Blake, S. Logan, G. Humphreys, J. Matthews, M. Rogers, J. Thompson-Coon, Wyatt k, C. Morris, et al., Sleep positioning systems for children with cerebral palsy, Cochrane Libr. (2015) 11.

[5] A.L. Tietze, M. Blankenburg, T. Hechler, E. Michel, M. Koh, B. Schlüter, et al., Sleep disturbances in children with multiple disabilities, Sleep Med. Rev. 16 (2012) $117-127$.

[6] S.W. Lockley, D.J. Skene, J. Arendt, et al., Relationship between melatonin rhythms and visual loss in the blind, J. Clin. Endocrin. 82 (1997) 3763-3770.

[7] D.M. Romeo, C. Brogna, M. Quintiliani, G. Baranello, E. Pagliano, T. Casalino, A. Sacco, D. Ricci, M. Mallardi, E. Musto, S. Sivo, F. Cota, D. Battaglia, O. Bruni, E. Mercuri, Sleep disorders in children with cerebral palsy: neurodevelopmental and behavioral correlates, Sleep Med. 15 (2) (2014) 213-218.

[8] E. Wirrell, M. Blackman, K. Barlow, et al., Sleep disturbances in children with epilepsy compared with their nearest-aged siblings, Dev. Med. Child Neurol. 47 (2005) 754-759.

[9] S. Kotagal, V.P. Gibbons, J.A. Stith, Sleep abnormalities in patients with severe cerebral palsy, Dev. Med. Child Neurol. 36 (1994) 304-311.

[10] C.L. Marcus, Sleep-disordered breathing in children, Am. J. Respir. Crit. Care Med. 164 (2001) 16-30.

[11] A.L. Lelís, M.V. Cardoso, W.A. Hall, Sleep disorders in children with cerebral palsy: an integrative review, Sleep Med. Rev. 11 (2015) 63-71.

[12] J. Garstang, M. Wallis, Randomized controlled trial of melatonin for children with autistic spectrum disorders and sleep problems, Child Care Health Dev. 32 (2006) 585-589.

[13] G.M. Zuculo, B.S.B. Gonçalves, C. Brittes, L. Menna-Barreto, L. Pinato, Melatonin and circadian rhythms in autism: case report, Chronobiol. Int. 34 (4) (2017) $527-530$.

[14] J. Axelrod, The pineal gland: a neurochemical transducer, Science 184 (1974) $1341-1348$.

[15] I.V. Zhdanova, H.J. Lynch, R.J. Wurtman, Melatonin: a sleep-promoting hormone, Sleep 20 (1997) 899-907.

[16] T. Shochat, I. Haimov, P. Lavie, Melatonin - the key to the gate of sleep, Ann. Med. 30 (1998) 109-114.
[17] O. Tzischinsky, A. Shlitner, P. Lavie, The association between the nocturnal sleep gate and nocturnal onset of urinary 6-sulfatoxymelatonin, J. Biol. Rhythms 8 (1993) 199-209.

[18] R.P. Markus, E. Cecon, M.A. Pires-Lapa, Immune-pineal axis: nuclear factor $\kappa B$ (NF$\mathrm{kB}$ ) mediates the shift in the melatonin source from pinealocytes to immune competent cells, Int. J. Mol. Sci. 14 (2013) 10979-10997.

[19] L. Pinato, S. da Silveira Cruz-Machado, D.G. Franco, L.M. Campos, E. Cecon, P.A. Fernandes, J.C. Bittencourt, R.P. Markus, Selective protection of the cerebellum against intracerebroventricular LPS is mediated by local melatonin synthesis, Brain Struct. Funct. 220 (2015) 827-840.

[20] A.L. Richdale, Sleep problems in autism: prevalence, cause, and intervention, Dev. Med. Child Neurol. 41 (1999) 60-66.

[21] J. Martin, H. Hiscock, P. Hardy, et al., Adverse associations of infant and child sleep problems and parent health: an Australian population study, Pediatrics 119 (2007) 947-955.

[22] A. Morley, Cerebral palsy and sleep disordered breathing, Breathe (Sheff) 12 (2016) $357-363$.

[23] O. Verschuren, P. Mc Phee, P. Rosenbaum, J.W. Gorter, The formula for health and well-being in individuals with cerebral palsy: physical activity, sleep, and nutrition, Dev. Med. Child Neurol. 58 (2016) 989-990.

[24] P. Rosenbaum, J.W. Gorter, The' F-words' in childhood disability: I swear this is how we should think, Child Care Health Dev. 38 (2012) 457-463.

[25] A.S. Belísio, F.M. Louzada, C.V.M. Azevedo, Influence of social factors on the sleepwake cycle in children, Sleep Sci. 3 (2010) 82-86.

[26] V.R. Ferreira, L.B. Carvalho, F. Ruotolo, J.F. de Morais, L.B. Prado, G.F. Prado, Sleep disturbance scale for children: translation, cultural adaptation, and validation, Sleep Med. 10 (2009) 457-463.

[27] E. Hiratuka, T.S. Matsukura, L.I. Pfeifer, Adaptação transcultural para o Brasil do sistema de classificação da função motora grossa GMFCS, Braz. J. Phys. Ther. 14 (2010) 537-544.

[28] R.J. Palisano, S.E. Hanna, P.L. Rosenbaum, D.J. Russell, S.D. Walter, E.P. Wood, et al., Validation of a model of Gross motor function for children with cerebral palsy, Phys. Ther. 80 (2000) 974-985.

[29] Rafaela Barroso Granzotti, Silva K. Guedes, et al., Cross-cultural adaptation of communication function classification system for individuals with cerebral palsy, Rev. CEFAC 8 (2016) 1020-1028.

[30] E. Barty, K. Caynes, L.M. Johnston, Development and reliability of the Functional Communication Classification System for children with cerebral palsy, Dev. Med. Child Neurol. 58 (2016) 1036-1041.

[31] D. Virella, L. Pennington, G.L. Andersen, G. Andrada Mda, A. Greitane, K. Himmelmann, et al., Classification systems of communication for use in epidemiological surveillance of children with cerebral palsy, Dev. Med. Child Neurol. 58 (2016) 285-291.

[32] S. Blunden, K. Lushington, B. Lorenzen, T. Ooi, F. Fung, D. Kennedy, Are sleep problems under-recognised in general practice? Arch. Dis. Child. 89 (2004) 708-712.

[33] A. Kahn, C. Van de Merckt, E. Rebuffa, M.J. Mozin, M. Sottiaux, D. Blum, et al., Sleep problems in healthy preadolescents, Pediatrics 84 (1989) 542-546.

[34] D.M. Romeo, C. Brogna, E. Musto, G. Baranello, E. Pagliano, T. Casalino, et al., Sleep disturbances in preschool age children with cerebral palsy: a questionnaire study, Sleep Med. 15 (2014) 1089-1093.

[35] C.J. Newman, M. O'Regan, O. Hensey, Sleep disorders in children with cerebral palsy, Dev. Med. Child Neurol. 48 (2006) 564-568.

[36] S.M. McCabe, A.M. Blackmore, C.R. Abbiss, K. Langdon, C. Elliott, Sleep concerns in children and young people with cerebral palsy in their home setting, J. Paediatr. Child Health 51 (2015) 1188-1194.

[37] M.A. Stein, J. Mendelsohn, W.H. Obermeyer, J. Amromin, R. Benca, Sleep and behavior problems in school-aged children, Pediatrics 107 (Apr (4)) (2001) E60.

[38] R.M. Elsayed, B.M. Hasanein, H.E. Sayyah, M.M. El-Auoty, N. Tharwat, T.M. Belal, Sleep assessment of children with cerebral palsy: using validated sleep questionnaire, Ann. Indian Acad. Neurol. 16 (2013) 62-65.

[39] G. Kontorinis, M.S. Thevasagayam, N.D. Bateman, Airway obstruction in children with cerebral palsy: need for tracheostomy? Int. J. Pediatr. Otorhinolaryngol. 77 (2013) 1647-1650.

[40] M. Wright, A. Tancredi, B. Yundt, H.M. Larin, Sleep issues in children with physical disabilities and their families, Phys. Occup. Ther. Pediatr. 26 (2006) 55-72.

[41] S.R. Shott, Evaluation and management of pediatric obstructive sleep apnea beyond tonsillectomy and adenoidectomy, Curr. Opin. Otolaryngol. Head Neck Surg. 19 (2011) 449-5454.

[42] T. Schlereth, M. Dieterich, F. Birklein, Hyperhidrosis-causes and treatment of enhanced sweating, Dtsch. Arztebel. Int. 106 (2009) 32-37.

[43] S. Schuh-Hofer, R. Wodarski, D.B. Pfau, O. Caspani, W. Magerl, J.D. Kennedy, R.D. Treede, One night of total sleep deprivation promotes a state of generalized hyperalgesia: a surrogate pain model to study the relationship of insomnia and pain, Pain 154 (2013) 1613-1621.

[44] B. Malow, K.W. Adkins, S.G. McGrew, L. Wang, S.E. Goldman, D. Fawkes, et al. Melatonin for sleep in children with autism: a controlled trial examining dose, tolerability, and outcomes, J. Autism Dev. Disord. 42 (2012) 1729-1737.

[45] S. Wayte, E. McCaughey, S. Holley, D. Annaz, C.M. Hill, Sleep problems in children with cerebral palsy and their relationship with maternal sleep and depression, Acta Paediatr. 101 (2012) 618-623. 